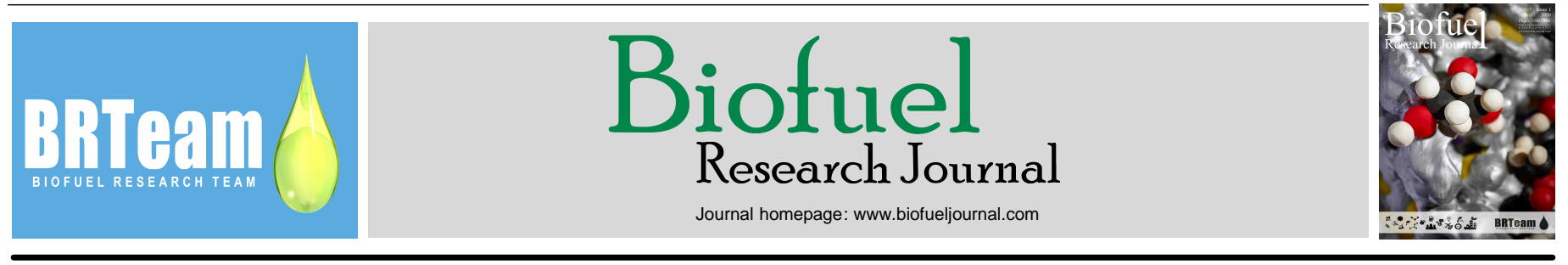

Original Research Paper

\title{
Selective evaporation of a butanol/water droplet by microwave irradiation, a step toward economizing biobutanol production
}

\author{
Yosuke Shibata $^{1}$, Kenya Tanaka ${ }^{1}$, Yusuke Asakuma ${ }^{1, *}$, Cuong V. Nguyen ${ }^{2}$, Son A. Hoang ${ }^{3}$, Chi M. Phan ${ }^{2, *}$ \\ ${ }^{1}$ Department of Chemical Engineering, University of Hyogo, 2167 Shosha, Himeji, Hyogo 671-2280, Japan. \\ ${ }^{2}$ Discipline of Chemical Engineering and Curtin Institute of Functional Molecules and Interfaces, Curtin University, GPO Box U1987, Perth, WA 6845, \\ Australia.
}

${ }^{3}$ Institute of Materials Science, Vietnam Academy of Science and Technology, 18 Hoang Quoc Viet Street, Cau Giay, Ha Noi, Vietnam.

\section{HIGHLIGHTS}

$>$ Surface and evaporation of alcohol/water was studied in-situ in response to microwave irradiation. $>$ Butanol content in liquid phase was reduced by approx. 90\%.

$>$ Similar trend was observed with pentanol/water droplet.

$>$ The method could be applied to improve efficiency of fermentative butanol separation.

\section{GRAPHICAL ABSTRACT}

Bulk evaporation using conventional pool boiling
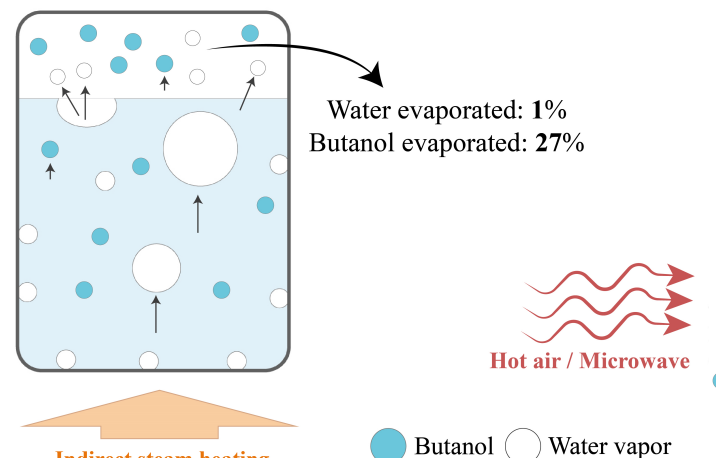

Indirect steam heating
Droplet evaporation using Microwave

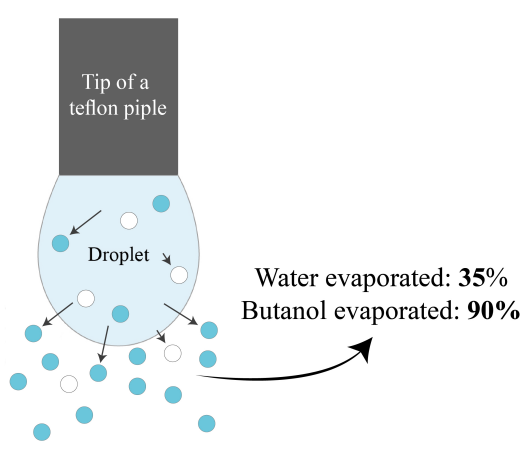

\section{ARTICLE INFO}

\section{Article history:}

Received 8 November 2019

Received in revised form 9 January 2020

Accepted 18 January 2020

Available online 1 March 2020

\section{Keywords:}

Microwave

Surface tension

1-butanol separation

Evaporation

Economic viability

\begin{abstract}
The separation step is a constraint in biobutanol production, due to high energy consumption of the current techniques. This study explores a new separation method via applying microwave irradiation. Butanol/water droplet was monitored during exposure to microwave irradiation at different power rates. The surface tension, droplet volume, and temperature were scrutinized during and after exposure to microwave irradiation. The data obtained indicated that the microwave-induced evaporation rates of alcohols were much higher than that of water. Consequently, the vaporized phase contained a much higher alcohol content than the liquid phase. In particular, butanol concentration in the aqueous phase could be reduced to $\sim 0.1 \mathrm{wt} . \%$, which was more effective than the theoretical limit via the boiling process. The method is an attractive option to complement the fermentation process, which produces a low butanol concentration solution. This development could potentially lead to a more efficient pathway for biobutanol production.
\end{abstract}

* Corresponding authors at: Tel.: +81 792674847 (Y. Asakuma) \& +61 892667571 (C.M. Phan)

E-mail address: asakuma@eng.u-hyogo.ac.jp (Y. Asakuma) \& c.phan@curtin.edu.au (C.M. Phan)

Please cite this article as: Shibata Y., Tanaka K., Asakuma Y., Nguyen C.V., Hoang S.A., Phan C.M. Selective evaporation of a butanol/water droplet by microwave irradiation, a strategy to economize biobutanol production. Biofuel Research Journal 25 (2020) 1109-1114. DOI: 10.18331/BRJ2020.7.1.3 


\section{Introduction}

Biofuels have been promoted as sustainable alternatives to fossil fuels to reduce the anthropogenic $\mathrm{CO}_{2}$ emissions. However, the two main biofuels, i.e., ethanol and biodiesel, require significant land usages and may compete with food production (Bringezu, 2009). These challenges have diverted some attention toward 1-butanol as a favorable biofuel. More specifically, in comparison with ethanol, butanol can be blended with conventional gasoline at higher concentrations without requiring engine retrofitting while it also has a high energy density (Kazemi Shariat Panahi et al., 2019). More importantly, biobutanol is more sustainable due to a variety of feasible feedstock. In addition to agricultural wastes, such as barley straw and corn stover (Qureshi et al., 2014), fermentative butanol can be produced by microalgae (Wang et al., 2017), and thus competition over arable could be avoided.

In spite of all the above-mentioned advantages, biobutanol production has remained uneconomical (Bharathiraja et al., 2017). The cost associated with the separation/purification step is regarded as the main obstacle of a successful biobutanol production (García et al., 2011). Butanol is less volatile than water, with a saturation pressure of $30 \%$ of water pressure at $20^{\circ} \mathrm{C}$ (Munday et al., 1980). The current butanol distillation method relies on conventional boiling with multiple steps (Xie et al., 2015). In this process, mixed liquid is fractioned by phase separation, via evaporation and condensation. Due to the high boiling point of 1-butanol, i.e., $118^{\circ} \mathrm{C}$, water will evaporate more significantly (Oudshoorn et al., 2009). The relative evaporation is disadvantageous for butanol production given the fact that the maximum concentration of butanol in the aqueous phase is only $\sim 70 \mathrm{~g} / \mathrm{L}$ (Barton and Haulait-Pirson, 1984; Sakashita et al., 2010; Bharathiraja et al., 2017) or 6 wt.\% (Cheng and Park, 2017). Furthermore, the biological process cannot tolerate high butanol concentrations. Typically, butanol concentration in the fermentative broth is limited to $\sim 1.5$ wt.\% (Mariano et al., 2012). As a result, a separation process via conventional distillation is highly uneconomical for fermentative butanol. Consequently, many separation techniques have been attempted to increase the process efficiency. These include pervaporation, adsorption/desorption, surfactant (cloud point) extraction, steam stripping distillation, liquid-liquid extraction and gas stripping (García et al., 2011). Among these methods, it has been theoretically estimated that adsorption is the most efficient process, at $1,948 \mathrm{kcal} / \mathrm{kg}$ butanol (Qureshi et al., 2005)

Most of these processes involve a phase conversion, in which energy is required to vaporize the liquid phase. In the conventional pool-boiling, the heat is applied to liquid bulk. During the process, bubbles are formed in bulk, before busting to the liquid surface (Mori and Utaka, 2017; Liang and Mudawar, 2019). Recently, surface evaporation, i.e., without bubble formation in bulk, has been examined. In this method, a liquid droplet can be evaporated without pool-boiling (Fig. 1), by contact with either a hot air flow (Nguyen et al., 2018) or microwave irradiations (Asakuma et al., 2016). This method does not require a bulk boiling and is more energy-efficient since it only heats the surface layer instead of the whole liquid bulk.

a

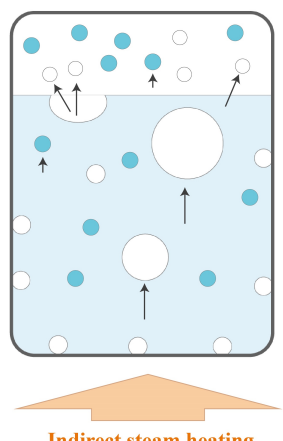

Indirect steam heating b

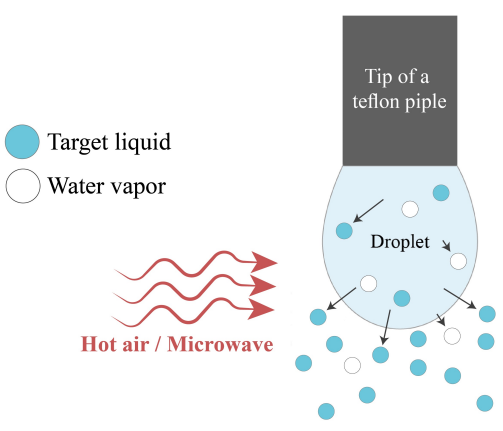

Fig. 1. Evaporation of liquid (a) conventional pool-boiling vs. (b) microwave/hot airflow.

One of the most interesting features of the microwave/hot airflow-assisted evaporation method is that selective evaporation of liquid mixtures, such as water/glycol (Asakuma et al., 2018) and water/glycerol (Nguyen et al., 2018) is feasible. These previous studies verified that the evaporation rate of the studied component would be dramatically changed along with a small change in its bulk concentration. Since these organics are amphiphilic, they can be adsorbed at the interface, i.e., acting as a weak surfactant and thus having a high surface concentration.

The surface adsorption of alkanols is well-known (Posner et al., 1952; Gliński et al., 1998; Strey et al., 1999; Habrdova et al., 2004; Le et al., 2012) and their surface tensions are shown in Figure 2. For 1-butanol, it has been verified that the surface tension of its aqueous solution can be reduced to $25 \mathrm{mN} / \mathrm{m}$ at the solubility of $6 \mathrm{wt} . \%$ (Cheng and Park, 2017). Hence, it is expected that alkanols are strongly adsorbed at the air/water surface (Lee e al., 2016) and have selective evaporation (Walz et al., 2015), even at low concentration conditions of fermentative broth.

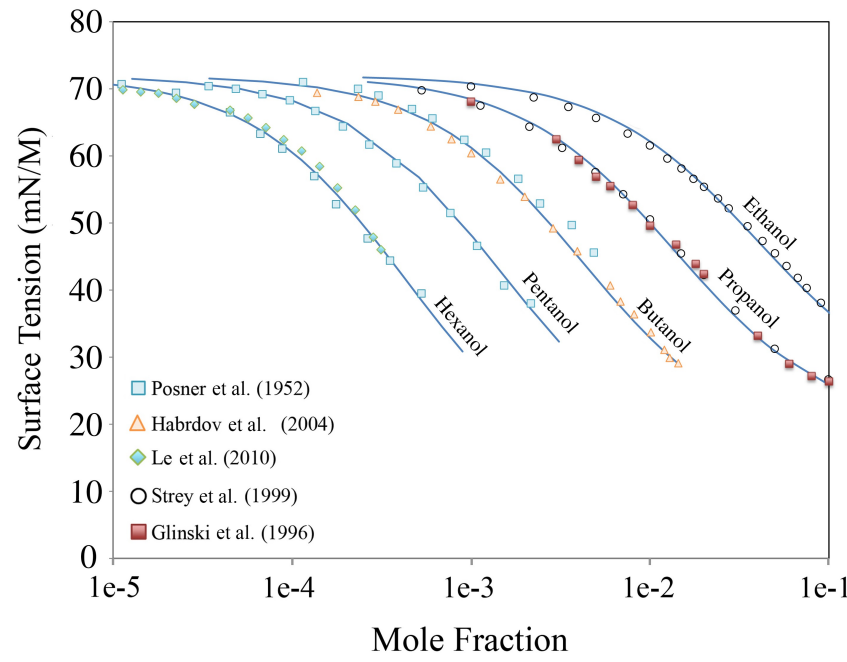

Fig. 2. Surface tension of alkanols at $25^{\circ} \mathrm{C}$ as reported in the literature (lines are empirical fitting curves).

Previously, microwave has been used to extract volatile compounds in the distillation-extraction process. The results have demonstrated a significant improvement over the conventional heating method, that is through conduction (Ferhat et al., 2007). Furthermore, microwave can focus the energy on the surface layer, where the evaporation process takes place, instead of heating the bulk liquid phase. The arrangement can reduce the energy required for the phase separation process. Due to the highly amphiphilic structure of butanol, it is expected that butanol molecules will adsorb microwave energy via molecular rotation and evaporate faster than water. On this basis, in this study, we apply the microwave irradiations to water/butanol droplet and quantify the in-situ temperature/surface tension. The new insights into surface evaporation of the mixture can lead to a new process to separate water/biobutanol. In addition to 1-butanol, the mixture of 1-pentanol/water was also investigated. Since 1-pentanol has a higher boiling point than water, it is expected that the data for 1-pentanol/water mixture can validate the influence of microwave irradiation on surface evaporation.

\section{Experimental}

The pendant drop of alcohol solution was hung at the tip of polytetrafluoroethylene (Teflon) pipe, with an outside diameter of $2 \mathrm{~mm}$ and inside diameter of $1 \mathrm{~mm}$. The droplet was placed at the centre of the microwave reactor. After placing the droplet (Parmar et al., 2014), an optic fibre was inserted inside the droplet through the Teflon pipe (Fig. 3). Accordingly, the temperature inside the droplet both during and after microwave irradiation could be monitored. A digital camera was employed to capture the shape of the droplet during and after microwave irradiation. The edge profiles of the droplet were analyzed by Axisymmetric Drop Shape Analysis (ADSA) to calculate its surface tension (Zuo et al., 2004). Experimental conditions of alcohol concentration and microwave are listed in Table 1. Low concentrations were selected due to the low solubility of 
alcohols. On the other hand, this concentration range covers typical concentrations of butanol in fermentation broth (Qureshi et al., 2005).

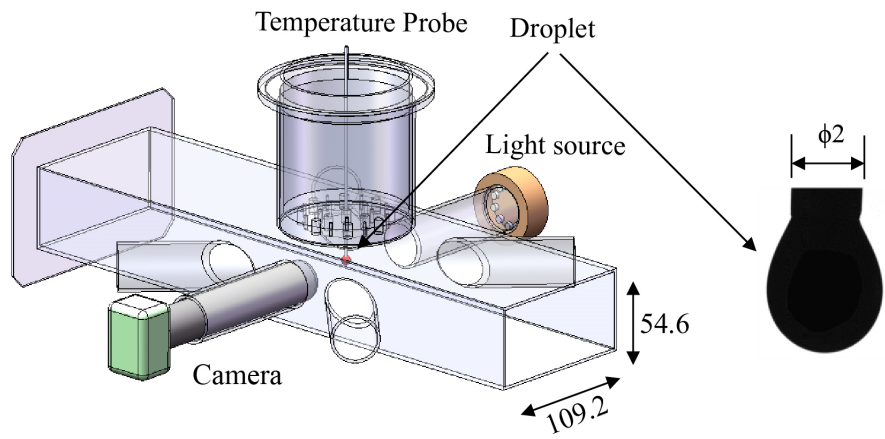

Fig. 3. Microwave reactor for $i n$-situ surface tension measurement.

Table 1.

Experimental conditions.

\begin{tabular}{lcccc}
\hline No. & Alcohol & $\begin{array}{c}\text { Concentration } \\
(\mathbf{w t .} \%)\end{array}$ & $\begin{array}{c}\text { Microwave Power } \\
(\mathbf{W})\end{array}$ & $\begin{array}{c}\text { Irradiation time } \\
(\mathbf{s})\end{array}$ \\
\hline 1 & 1-Butanol & 0.1 & $50,100,150,300$ & 120 \\
2 & 1-Butanol & 0.8 & $50,100,150,300$ & 120 \\
3 & 1-Butanol & 1.5 & $50,100,150,300$ & 120 \\
4 & 1-Pentanol & 0.1 & $50,100,150,300$ & 120 \\
5 & 1-Pentanol & 0.3 & $50,100,150,300$ & 120 \\
6 & 1-Pentanol & 0.5 & $50,100,150,300$ & 120 \\
\hline
\end{tabular}

\section{Results and Discussion}

Figure 4a shows the surface tension of a butanol/water droplet as a function of time. Solid symbols and unfilled symbols represent the data during and after the irradiation, respectively. The transient temperature was also recorded and used to plot the tension-vs.-temperature profile (Fig. 4b). In addition to our results, the data obtained by conventional heating are also included (Ono et al., 2009). During the first $20 \mathrm{~s}$ of microwave irradiation, the surface tension decreased prior to a rapid increase. The initial decrement was prominently caused by the increase in droplet's temperature. This temperature increment may enhance the adsorption of the alcohol to the surface, decrease the cohesive forces (Ghatee et al., 2010), leading to a reduction in surface tension. However, the increment of surface tension after $20 \mathrm{~s}$ indicated that the alcohol adsorption was reduced. It is noteworthy that such tension increment is contrasting to the behavior of a pure liquid droplet, such as water and glycol (Parmar et al., 2014). The tension increment indicated that adsorbed butanol molecules were vaporized to the surrounding air. The evaporation rate of alcohol was much higher than that of water. This evaporation reaches the highest point at a specific temperature for each microwave power. This temperature is demonstrated by a vertical section in the tension-versus-temperature data (Fig. $4 \mathrm{~b}$ ). For instance, the corresponding temperatures of 50, 100, and $150 \mathrm{~W}$ were 47,58 and $68^{\circ} \mathrm{C}$, respectively. For $300 \mathrm{~W}$, the data were leaning backwards, which indicated that the droplet temperature was dropping before the microwave was turned off. In this instance, the evaporation rate was so high that the droplet was cooled down, from 80 to $70^{\circ} \mathrm{C}$, during microwave irradiation. After the microwave was turned off at $120 \mathrm{~s}$, the evaporation was quickly reduced. A similar effect can be observed in the case of 1-pentanol (Fig. 5).

Alcohol concentrations after microwave irradiation were calculated by the value of surface tension through the correlation between the concentration and surface tension (in Fig. 2). Accordingly, it was found that the alcohol content was reduced significantly. The data were compared with theoretical liquid concentrations via boiling, generated by Aspen-HYSYS using UNIQUAC coefficient (Anderson and Prausnitz, 1978). It can be seen that microwave

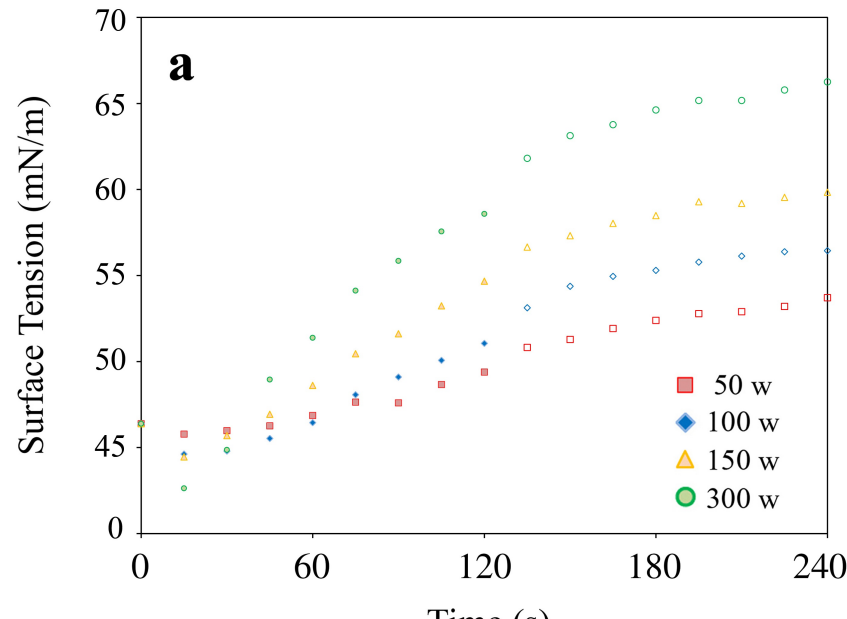

Time (s)

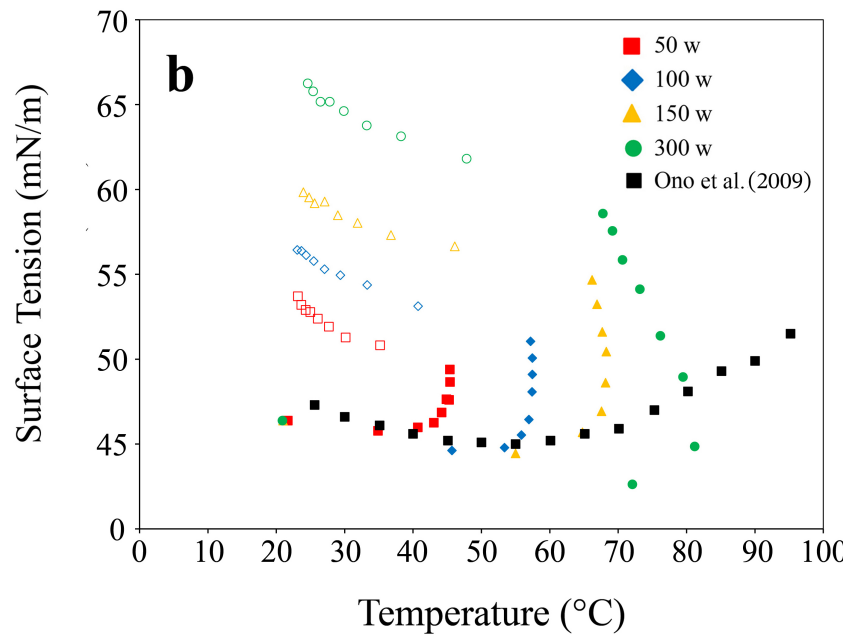

Fig. 4. Surface tension of 1-butanol solution (1.5 wt.\%) droplet for different irradiation powers as a function of (a) time and (b) temperature (Solid Symbols: during MW, Unfilled Symbols: after MW). The black squares in Figure $4 \mathrm{~b}$ represent the surface tension via the maximum bubble method, which excluded the evaporation (Ono et al., 2009).

irradiation can reduce alcohol content far lower than the corresponding thermodynamic equilibrium at 98 and $99^{\circ} \mathrm{C}$. Furthermore, the microwaveinduced evaporation was achieved at a liquid temperature around $80^{\circ} \mathrm{C}$ (Fig. 6), which is much lower than the boiling point of water.

From the volume of droplet, the evaporation of water was also calculated for comparison (Fig. 7). For 1.5 wt.\% 1-butanol droplet, the alcohol concentration was reduced to $0.16 \mathrm{wt} . \%$ by $300 \mathrm{~W}$ irradiation, or in another word, $~ 90 \%$ of butanol was evaporated, comparing to $35 \%$ of evaporated water. The mass ratio between the evaporated butanol and water was $4.9 \%$. In another word, the microwave enriched the butanol concentration from 1.5 wt.\% to 4.9 wt.\% (Fig. 7a). For pentanol/water mixtures, the vapor phase also contained more pentanol than water. However, the enrichment ratio was much less (Fig. 7b) than 1-butanol due to the higher molecular weight of pentanol.

It has been well-accepted that microwave irradiations heat liquids by friction between rotating molecules. Consequently, the highest friction occurs in the interfacial region, such as water/oil or water/solid interfaces (Hyde et al., 2017). It should be noted that the observed evaporation rate herein was much higher than the evaporation of butanol/water droplet in contact with hot air flow (Nguyen, 2018). At these layers, molecules with different polarities will rotate at different rates and produce higher friction (Marek and Straub, 2001). The same mechanism is expected at the water/butanol surface, due to the enhanced butanol concentration. As a result, the alcohol molecules in the interfacial layer evaporate faster. 

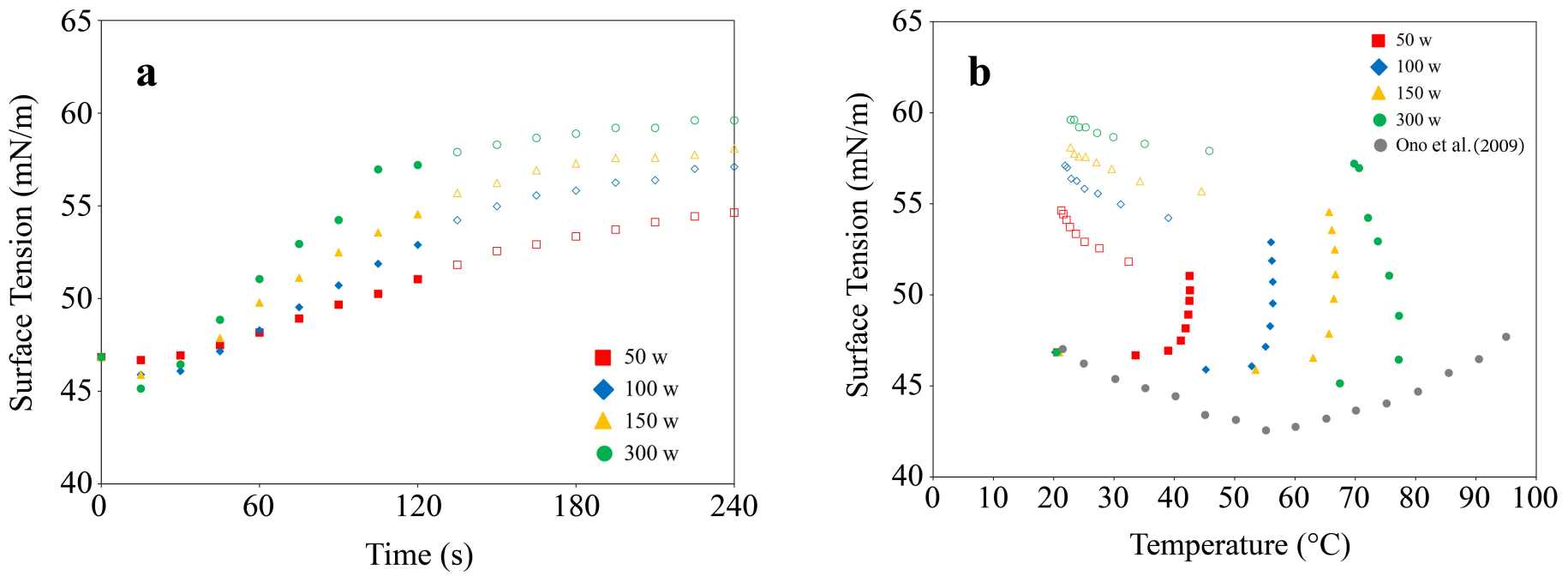

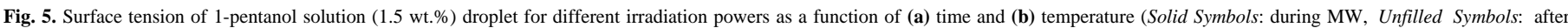
MW). The gray circles in Figure 5b represent the surface tension via the maximum bubble method (Ono et al., 2009).
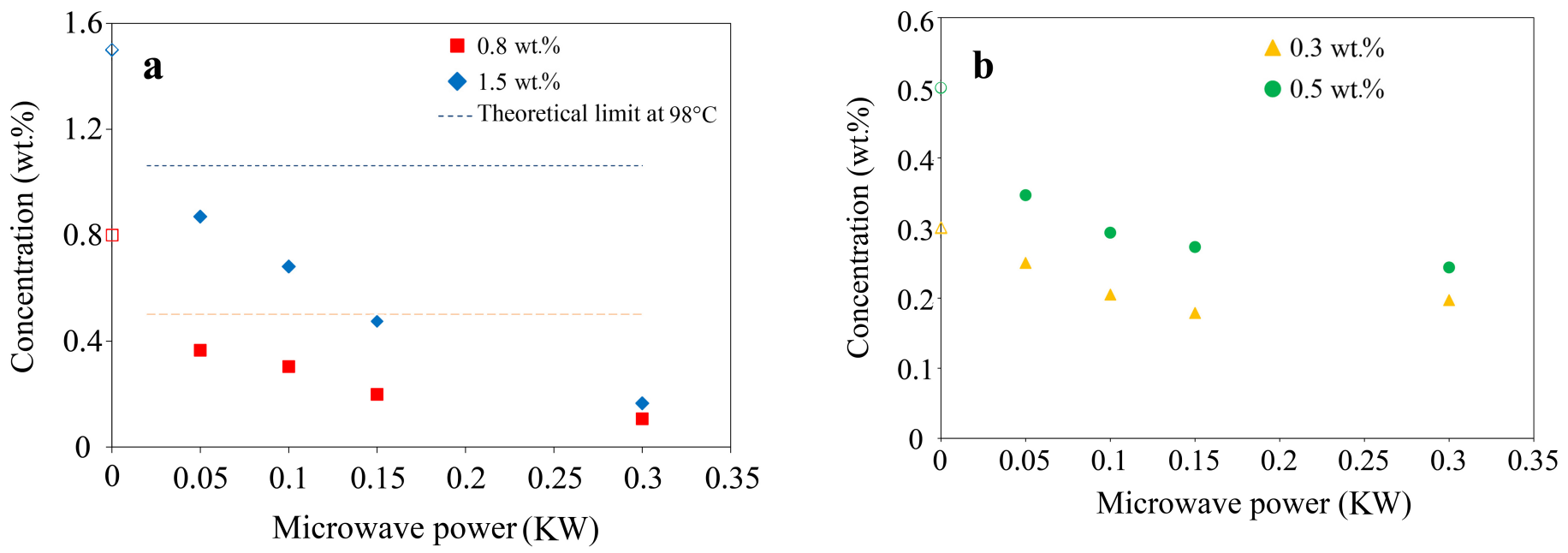

Fig. 6. Predicted alcohol concentration after microwave (a) 1-butanol (the horizontal lines represent the theoretical 1-butanol concentration in liquid phase) and (b) 1-pentanol.
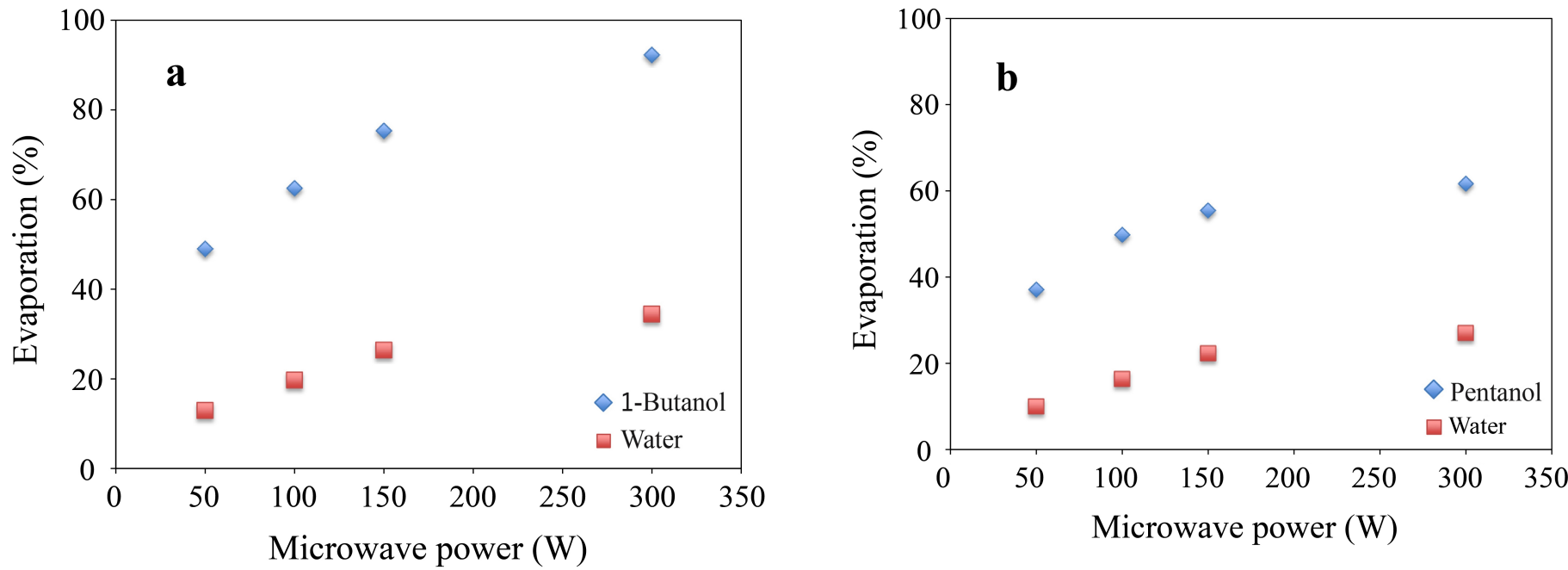

Fig. 7. Component evaporation of (a) $1.5 \mathrm{wt} . \%$ 1-butanol droplet and (b) $0.5 \mathrm{wt} . \%$ 1-pentanol droplet. 
It should be noted that the current separation techniques are not easy to apply simultaneously with the fermentation process due to the potential loss of nutrients and fermentation intermediates (Kazemi Shariat Panahi et al., 2019). Consequently, researchers have to rely on a reduced vacuum to enhance the gas stripping process (Mariano et al., 2012). Adjusting pressure may shift the microwave separation favorably. Furthermore, the addition of electrolyte can enhance alcohol adsorption at the solution surface (Gao et al., 2017) and increase alcohol evaporation. Further experiments at different conditions are recommended to improve separation and energy efficiency.

\section{Conclusions}

An aqueous droplet containing 1-butanol was exposed to microwave irradiations. The surface tension indicated that the adsorbed alcohols evaporated quickly during microwave irradiation. The evaporation was reduced during the post-microwave cooling period. The results obtained demonstrated that microwave could be used to evaporate 1-butanol/water selectively. The vapor phase had a higher butanol concentration than the aqueous phase. For example, $1.5 \mathrm{wt}$. \% butanol solution could produce a vapor phase with $4.9 \mathrm{wt} . \%$ butanol. While the selective evaporation could not completely separate butanol from water, the enriched butanol in the vapor phase could undergo other separation processes for biofuel production.

\section{Acknowledgements}

The authors acknowledge Prof. Naoki Ono (Shibaura Institute of Technology) and Dr. Tuyen Pham (Newcastle University, Australia) for sharing their data.

\section{References}

[1] Anderson, T.F., Prausnitz, J.M., 1978. Application of the UNIQUAC equation to calculation of multicomponent phase equilibria. 1. vaporliquid equilibria. Ind. Eng. Chem. Process Des. Dev. 17(4), 552-561.

[2] Asakuma, Y., Nakata, R., Asada, M., Kanazawa, Y., Phan, C., 2016. Bubble formation and interface phenomena of aqueous solution under microwave irradiation. Int. J. Heat Mass Transfer. 103, 411-416.

[3] Asakuma, Y., Matsumura, S., Asada, M., Phan, C., 2018. In situ investigation of microwave impacts on ethylene glycol aqueous solutions. Int. J. Thermophys. 39(2), 21.

[4] Barton, A.F.M., Haulait-Pirson, M.C., 1984. Alcohols with water. Pergamon.

[5] Bharathiraja, B., Jayamuthunagai, J., Sudharsanaa, T., Bharghavi, A., Praveenkumar, R., Chakravarthy, M., Yuvaraj, D., 2017. Biobutanol-an impending biofuel for future: a review on upstream and downstream processing tecniques. Renew. Sust. Energy Rev. 68, 788-807.

[6] Bringezu, S. (ed.), 2009. Towards sustainable production and use of resources: assessing biofuels. UNEP/Earthprint. United Nations Environment Programme.

[7] Cheng, K.K., Park, C., 2017. Surface tension of dilute alcohol-aqueous binary fluids: n-Butanol/water, n-Pentanol/water, and n-Hexanol/water solutions. Heat Mass Transfer. 53(7), 2255-2263.

[8] Ferhat, M.A., Tigrine-Kordjani, N., Chemat, S., Meklati, B., Chemat, F., 2007. Rapid extraction of volatile compounds using a new simultaneous microwave distillation: solvent extraction device. Chromatographia. $65(3-4), 217-222$

[9] Gao, G., Nguyen, C.V., Phan, C.M., 2017. Molecular arrangement between electrolyte and alcohol at the air/water interface. J. Mol. Liq. $242,859-867$

[10] García, V., Päkkilä, J., Ojamo, H., Muurinen, E., Keiski, R.L., 2011. Challenges in biobutanol production: how to improve the efficiency?. Renew. Sust. Energy Rev. 15(2), 964-980

[11] Ghatee, M.H., Zare, M., Zolghadr, A.R., Moosavi, F., 2010. Temperature dependence of viscosity and relation with the surface tension of ionic liquids. Fluid Phase Equilib. 291(2), 188-194.

[12] Gliński, J., Chavepeyer, G., Platten, J.K., Smet, P., 1998. Surface properties of diluted aqueous solutions of normal short-chained alcohols. J. Chem. Phys. 109(12), 5050-5053.
[13] Habrdová, K., Hovorka, Š., Bartovská, L., 2004. Concentration dependence of surface tension for very dilute aqueous solutions of organic nonelectrolytes. J. Chem. Eng. Data. 49(4), 1003-1007.

[14] Hyde, A., Horiguchi, M., Minamishima, N., Asakuma, Y., Phan, C. 2017. Effects of microwave irradiation on the decane-water interface in the presence of Triton X-100. Colloids Surf. A. 524, 178-184.

[15] Kazemi Shariat Panahi, H., Dehhaghi, M., Kinder, J.E., Ezeji, T.C., 2019. A review on green liquid fuels for the transportation sector: a prospect of microbial solutions to climate change. Biofuel Res. J. 6(3), 995-1024.

[16] Le, T.N., Phan, C.M., Ang, H.M., 2012.Influence of hydrophobic tail on the adsorption of isomeric alcohols at air/water interface. Asia-Pac. J. Chem. Eng. 7(2), 250-255.

[17] Lee, M.T., Orlando, F., Artiglia, L., Chen, S., Ammann, M. 2016. Chemical composition and properties of the liquid-vapor interface of aqueous $\mathrm{C} 1$ to $\mathrm{C} 4$ monofunctional acid and alcoho solutions. J. Phys. Chem. A. 120(49), 9749-9758.

[18] Liang, G., Mudawar, I., 2019. Review of pool boiling enhancement by surface modification. Int. J. Heat Mass Transfer. 128, 892-933.

[19] Marek, R., Straub, J., 2001. Analysis of the evaporation coefficient and the condensation coefficient of water. Int. J. Heat Mass Transfer. 44(1), 39-53

[20] Mariano, A.P., Qureshi, N., Maciel Filho, R., Ezeji, T.C., 2012. Assessment of in situ butanol recovery by vacuum during acetone butanol ethanol (ABE) fermentation. J. Chem. Technol Biotechnol. 87(3), 334-340

[21] Mori, S., Utaka, Y., 2017. Critical heat flux enhancement by surface modification in a saturated pool boiling: a review. Int. J. Heat Mass Transfer. 108, 2534-2557

[22] Munday, E.B., Mullins, J.C., Edle, D.D., 1980. Vapor pressure data for toluene, 1-pentanol, 1-butanol, water, and 1-propanol and for the water and 1-propanol system from 273.15 to 323.15 Vapor Pressure Data for Toluene, 1-Pentanol, 1-Butanol, Water, and 1-Propanol and for the Water and 1-Propanol Syst. J. Chem. Eng. Data. 25(3), 191194.

[23] Nguyen, T.T., Mitra, S., Sathe, M.J., Pareek, V., Joshi, J.B., Evans, G.M., 2018. Evaporation of a suspended binary mixture droplet in a heated flowing gas stream. Exp. Therm. Fluid Sci. 91, 32-344.

[24] Nguyen, T.T.B., 2018. Vaporisation of single and binary component droplets in heated flowing gas stream and on solid sphere. The University of Newcastle.

[25] Ono, N., Kaneko, T., Nishiguchi, S., Shoji, M., 2009. Surface tension of alcohol aqueous solutions by maximum bubble pressure method. J. Therm. Sci. Technol. 4(2), 284-293.

[26] Oudshoorn, A., Van Der Wielen, L.A., Straathof, A.J.J., 2009 Assessment of options for selective 1-butanol recovery from aqueous solution. Ind. Eng. Chem. Res. 48(15), 7325-7336.

[27] Parmar, H., Asada, M., Kanazawa, Y., Asakuma, Y., Phan, C.M., Pareek, V., Evans, G.M., 2014. Influence of microwaves on the water surface tension. Langmuir. 30(33), 9875-9879.

[28] Posner, A.M., Anderson, J.R., Alexander, A.E., 1952. The surface tension and surface potential of aqueous solutions of normal aliphatic alcohols. J. Colloid Sci. 7(6), 623-644

[29] Qureshi, N., Hughes, S., Maddox, I.S., Cotta, M.A., 2005. Energyefficient recovery of butanol from model solutions and fermentation broth by adsorption. Bioprocess. Biosys. Eng. 27(4), 215-222.

[30] Qureshi, N., Cotta, M.A., Saha, B.C., 2014. Bioconversion of barley straw and corn stover to butanol (a biofuel) in integrated fermentation and simultaneous product recovery bioreactors. Food and Bioproducts Processing. Inst. Chem. Eng. 92(3), 298-308.

[31] Sakashita, H., Ono, A., Nakabayashi, Y., 2010. Measurements of critical heat flux and liquid-vapor structure near the heating surface in pool boiling of 2-propanol/water mixtures. Int. J. Heat Mass Transfer. 53(7-8), 1554-1562.

[32] Strey, R., Viisanen, Y., Aratono, M., Kratohvil, J.P., Yin, Q., Friberg, S.E., 1999. On the necessity of using activities in the Gibbs equation. J. Phys. Chem. B. 103(43), 9112-9116.

[33] Walz, M.M., Caleman, C., Werner, J., Ekholm, V., Lundberg, D., Prisle, N.L., Öhrwall, G., Björneholm, O., 2015. behavior of 
amphiphiles in aqueous solution: a comparison between different pentanol isomers. Phys. Chem. Chem. Phys. 17(21), 14036-14044.

[34] Wang, Y., Ho, S.H., Yen, H.W., Nagarajan, D., Ren, N.Q., Li, S., Hu, Z., Lee, D.J., Kondo, A., Chang, J.S., 2017. Current advances on fermentative biobutanol production using third generation feedstock. Biotechnol. Adv. 35(8), 1049-1059.
[35] Xie, S., Qiu, X., Yi, C., 2015. Separation of a biofuel: recovery of biobutanol by salting-out and distillation. Chem. Eng. Technol. 38(12), 2181-2188.

[36] Zuo, Y.Y., Ding, M., Bateni, A., Hoorfar, M., Neumann, A.W. 2004. Improvement of interfacial tension measurement using a captive bubble in conjunction with axisymmetric drop shape analysis (ADSA). Colloids Surf. A. 250(1-3), 233-246. 